\title{
Neurological teratogenic effects of antiepileptic drugs during pregnancy (Review)
}

\author{
QINGMEI NIE ${ }^{1}$, BAOHUA SU $^{2}$ and JIANPING WEI ${ }^{3}$ \\ Departments of ${ }^{1}$ Emergency, ${ }^{2}$ Hematology and ${ }^{3}$ Emergency Neurology, \\ Weifang People's Hospital, Weifang, Shandong 261000, P.R. China
}

Received April 19, 2016; Accepted August 22, 2016

DOI: $10.3892 /$ etm.2016.3628

\begin{abstract}
Epilepsy is one of the few neurologic disorders that requires a constant treatment during pregnancy. Epilepsy affects $0.3-0.8 \%$ of pregnant women. Prescription of antiepileptic drugs (AEDs) to pregnant women with epilepsy requires monitoring and maintaining a balance between limiting seizures and decreasing fetal exposure to the potential teratogenic effects. AEDs are also commonly used for psychiatric disorders, pain disorders, and migraines. The types of malformations that can result in fetuses exposed to AEDs include minor anomalies, major congenital malformations, intrauterine growth retardation, cognitive dysfunction, low IQ, microcephaly, and infant mortality. In the present review, we analyzed and summarized the current understanding of neurological development in fetuses that are exposed to various AEDs administered to pregnant epileptic women.
\end{abstract}

\section{Contents}

1. Introduction

2. AED induced birth defects

3. Neurobehavioral endpoints with AEDs

4. Effects of different AEDs on neural defects

5. Phenobarbital

6. Valproic acid

7. Carbamazepine

8. Lamotrigine

9. Phenytoin

10. Topiramate

11. Vigabatrin

12. Conclusion

Correspondence to: Dr Jianping Wei, Department of Emergency Neurology, Weifang People's Hospital, 151 Guangwen Street, Weifang, Shandong 261000, P.R. China

E-mail: wei_jianping1@163.com

Key words: neurology, epilepsy, antiepileptic drugs, AEDs, pregnancy, teratology

\section{Introduction}

In the United States, mothers with epilepsy give birth to more than 30,000 children/year. Antiepileptic drugs (AEDs) are a class of drugs that are used to treat epilepsy in patients. AEDs are administered to most epileptic patients, including pregnant women; however, they can have negative consequence to fetuses in utero (1). AEDs are also used to treat other diseases as well such as neuropathic pain, migraines and psychiatric disorders, which means that AEDs can affect other pregnancies as well (2). Therefore, many pregnant women are being exposed to the potential dangerous effects of AEDs to the fetuses. However, AEDs are important for the treatment of epilepsy in pregnant mothers. Most women with epilepsy require AEDs to control seizures the entire length of the pregnancy. The most concerning issue in pregnant women with epilepsy is the development of tonic-clonic seizures, which can lead to dangerous issues for the fetus such as intracranial hemorrhage, transient hemorrhage and heart beat abnormalities $(3,4)$.

There may be multiple mechanisms through which AEDs affect fetal neurodevelopment. While scientists have still not properly characterized the pathways through which this may occur, a number of studies have investigated the mechanism through which this may occur. Cognitive defects can still occur in fetuses that are exposed to AED dosages that are lower than those that produce structural abnormalities. There are various hypothesis that have been set forward that may explain the ability of AEDs to produce functional defects; these may include suppression of neurons, ischemic condition in utero, formation of free radicals, apoptosis in neurons and decreased folate metabolism (Fig. 1) (5).

\section{AED induced birth defects}

The statistics for pregnant women taking AEDs are morbid, as $30 \%$ of pregnancies result in maternal mortality and $50 \%$ result in fetus mortality (6). Despite these odds, the majority of doctors encourage the use of AEDs during pregnancy. This is because, generally, women with epilepsy have normal childbirths and the offspring are born without any structural abnormalities. However, compared to a normal pregnancy, there is still a higher chance of the children to be born with birth defects (4). 


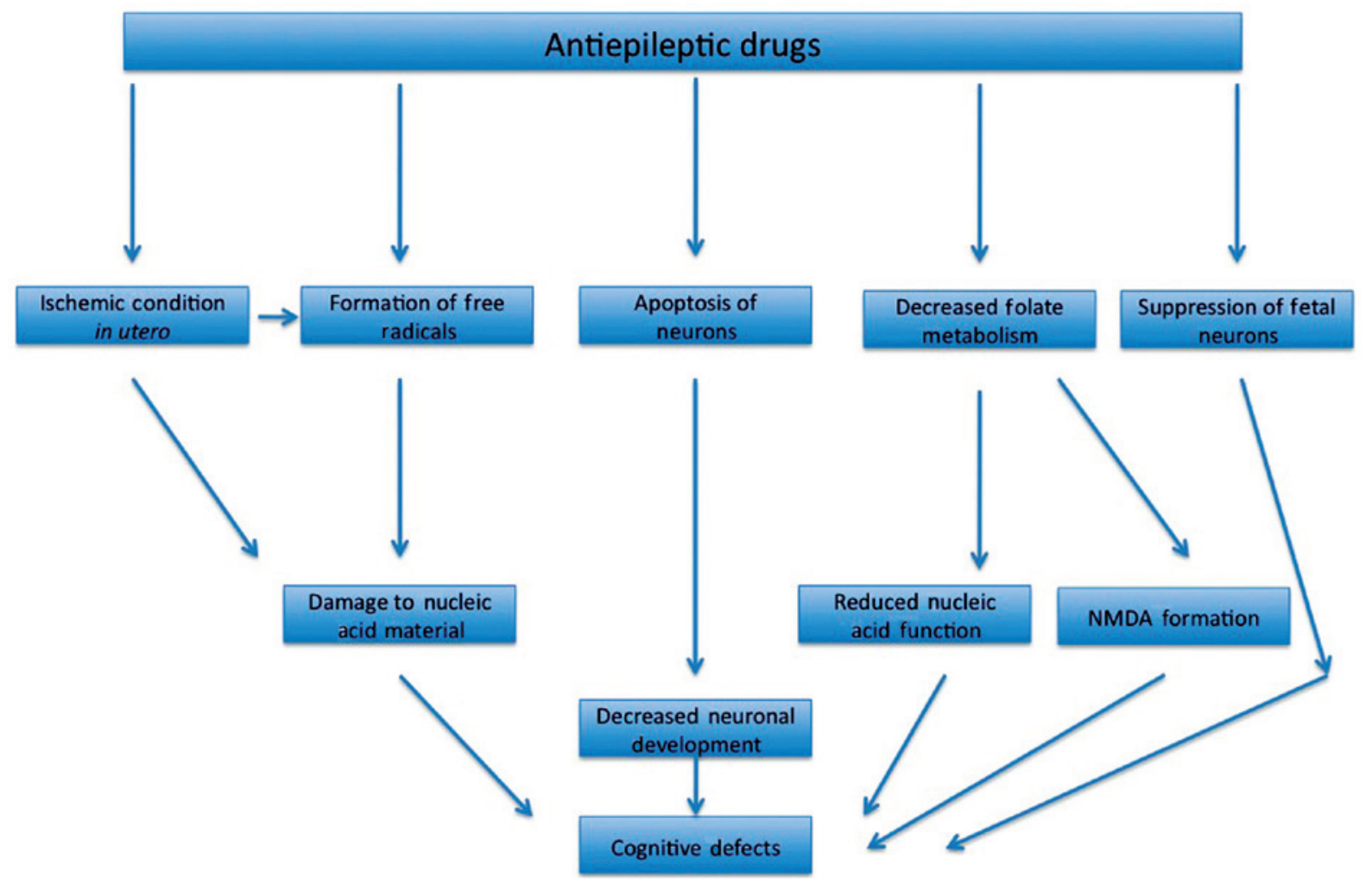

Figure 1. Various hypotheses that explain the teratogenecity of AEDs. There may be multiple mechanisms that lead to the formation of cognitive defects in fetuses, including ischemic condition, neural suppression, decreased folate absorption, neural apoptosis and an increase in free radical formation (5). AEDs, antiepileptic drugs.

A meta-analysis found that pregnant women with epilepsy that are on AEDs have a $6.1 \%$ chance of the development of major congenital malformations (7). Different AEDs have a different major congenital malformation rate (Fig. 1). Women with epilepsy that are not on AEDs have a $2.8 \%$ rate of major congenital malformation, which is slightly higher than the control group at $2.2 \%$ (8). When only treated with one AED (AED monotherapy), the prevalence of major congenital malformations is $3.7 \%$ while it is $6 \%$ in pregnant women that are treated with AED polytherapy. The types of malformations that are observed due to AED exposure in utero include cardiac malformations, hypospadias and facial clefts (9). The potential effects of some AEDs have been well-established but the effects of others remain unclear. One particular example of a specific malformation is the use of the drug valproate, which causes a 1-2\% risk of neural tube defects (10) (Table I).

\section{Neurobehavioral endpoints with AEDs}

Evidence from a variety of studies has shown that there is a definite correlation between the in utero exposure to various AEDs and the risk of cognitive and behavioral problems in children (6,11). The Kerala Registry of Epilepsy and Pregnancy conducted a study and determined that children that were exposed to AEDs in utero had the lowest mental development scores when compared to healthy controls (12). The mental development scores were found to be the lowest in children that were exposed to valproic acid. The mental development scores in children exposed to valproic acid were decreased by $40.8 \%$ when compared to controls. Other AEDs
Table I. Major congenital malformation rate due to in utero exposure to various AEDs.

Antiepileptic drug MCM rate (\%)

Carbamazepine

Valproic acid

Lamotrigine

Phenytoin

Gabapentin

Topiramate

7.10

These AEDs include carbamazepine, valproic acid, lamotrigine, phenytoin, gabapentin and topiramate (7). AEDs, antiepileptic drugs.

such as phenytoin, carbamazepine and phenobarbital also led to decreased mental development scores by 37, 29 and $26 \%$, respectively (12).

Another study conducted by Meador et al demonstrated that at the age of 3 , children that were exposed to the AED valproic acid in utero had the lowest IQ score. The mean IQ score for fetuses exposed to valproic acid was 92, which was 7 and 9 points lower, respectively, than the children that were exposed to carbamazepine and lamotrigine (5). In fact, the IQ of the offspring correlated with the mother's IQ in every case except for the exposure to valproic acid. Thirteen percent of children that were exposed in utero to valproic acid presented 


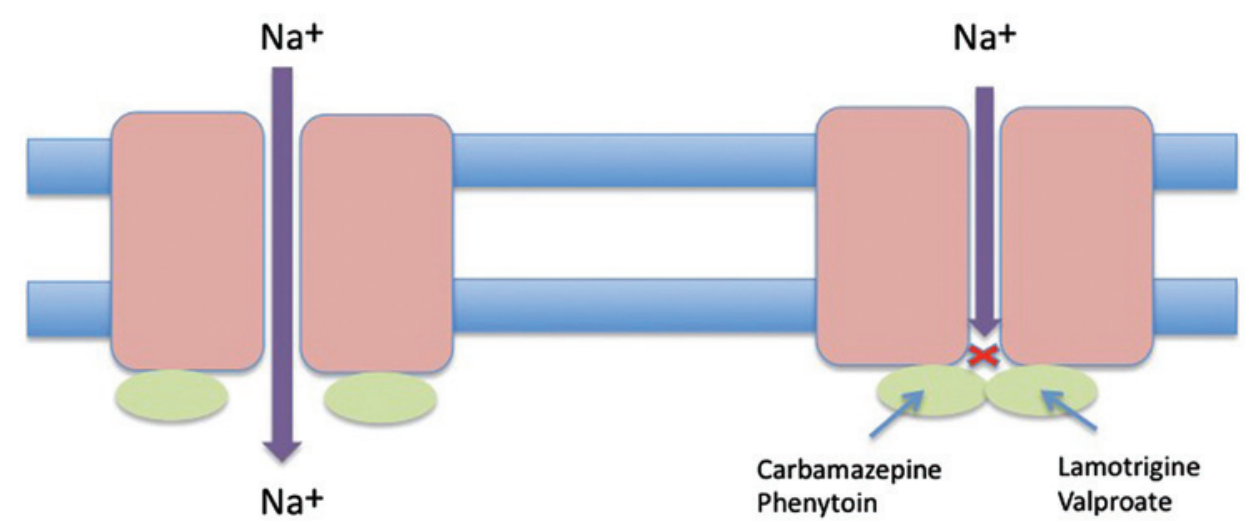

Figure 2. Mechanism of AEDs. Carbamazepine, phenytoin, lamotrigine and valproate work by inactivating voltage-gated sodium channels (18). AEDs, antiepileptic drugs.

with IQs that were in the impaired range; this is contrasted to $5 \%$ of children that were exposed to phenytoin, $3 \%$ of children that were exposed to carbamazepine and $2 \%$ of children that were exposed to lamotrigine $(5,13)$. Another study tested the ability of children exposed in utero to AEDs to generate quantity and quality of ideas. The study showed that both the quantity and quality of ideas were lower in children that were exposed to valproic acid when compared to the children that were exposed to lamotrigine and carbamazepine. Even in studies done in older children, AED in utero exposure was found to lead to altered cognitive function (14). Gaily et al found that older children that were exposed to monotherapy in utero had decreased performance on attentional tasks while being exposed to polytherapy led to decreased performance in auditory attention, sentence repetition and fine motor task (15). Long-term studies have shown that all AEDs, except for cabamazepine, led to a negative result in terms of intellectual function (16).

\section{Effects of different AEDs on neural defects}

There are various AEDs that have been investigated due to their potential for teratogenicity in pregnant women. Due to the fact that AEDs should not be discontinued during pregnancy, this is an issue that needs to be elaborated on extensively. The AEDs that we discuss in this review are phenobarbital, valproate, carbamazepine, lamotrigine, phenytoin and topiramate. The mechanism by which these drugs impart their action is by inhibiting the voltage-gated sodium channel (Fig. 2) (17).

\section{Phenobarbital}

Phenobarbital is one of the oldest AEDs that have been used to treat epilepsy in all patient cohorts. The effect of phenobarbital on fetuses was not evaluated until the 1970s. A study performed on pregnant mice using phenobarbital suggests that it leads to a $4.3 \%$ increase in incidences of cleft palates in fetuses (18). Phenobarbital exposure to pregnant rats has also led to an increased incidence of fetus mortality, impaired growth and delayed motor development. The mechanism behind phenobarbital-induced neural issues in the fetus may be related to the upregulation of cytochrome $\mathrm{P} 450$ s of the $2 \mathrm{~B}$ family. It may act to produce oxidative stress by generating superoxide radicals, which leads to the production of hydroxyl radicals. This causes GC to TA transversions, which may eventually lead to developmental defects $(19,20)$.

\section{Valproic acid}

Valproic acid and its various analogs and metabolites have been researched regarding their ability to assert a teratogenic effect. In order to be teratogenic, the drug needs to have the following components: A free carboxyl group, an $\alpha$-hydrogen atom, branching of carbon chains, no double bonds on C-2 or C-3 and an alkyl substituent on the C-2 that is larger than the methyl groups (21). Valproic acid and its effects have been analyzed across various animal systems such as zebrafish, mouse, rat, hamster and others (22-26). When valproic acid is administered at high enough dosages, such as those between 200-800 mg/day in mice, valproic acid induces various developmental defects, such as skeletal defects in craniofacial bones, in a dose-dependent manner. Increased doses of valproic acid were also found to lead to intra-uterine growth retardation, craniofacial, skeletal and cardiac defects (27).

In addition, rodents that were exposed to valproic acid were found to have fetuses that presented with neural tube defects. Valproic acid administration, when administered during early neural tube formation, can lead to exencephaly. Neural tube defects were found to be caused by $>225 \mu \mathrm{g} / \mathrm{ml}$ of valproic acid, which is above the concentration recommended for humans. The mechanism of the neural tube defect induced by valproic acid may be a result of altered folate metabolism in the embryo by increasing the tetrahydrofolate levels and decreasing levels of 5-formyl- and 10-formyltetrahydrofolates (28).

\section{Carbamazepine}

Carbamazepine, which is used as treatment for epilepsy and bipolar disorder, has been reported to lead to congenital abnormalities when used during pregnancies. Many articles have reviewed the first trimester exposure to carbamazepine and found that there was an increase in malformations such as neural tube defects, developmental delays, craniofacial defects and behavioral changes (29). A study by Diav-Citrin et al found that a cohort of pregnant women treated with carbamazepine showed a lack of neural tube defects, though that may 
be due to sample size limitation (30). Another study showed that offspring of epileptic pregnant women that were treated with carbamazepine led to a $10-\mathrm{mm}$ decrease in fetal head circumference, which did not become normal by the age of 18 months (31). Other studies have also found that carbamazepine exposure in utero has led to craniofacial defects and developmental delays. Therefore, carbamazepine is considered a human teratogen as it leads to major and minor abnormalities in fetuses and babies such as developmental problems, abnormal IQ and growth retardation (32).

\section{Lamotrigine}

Lamotrigine is one the newer AEDs and therefore, there is not much long-term information available on its effect on fetus development. GlaxoSmithKline (London, UK) began a database of women on lamotrigine in 1992, which is where much of the current data on this drug originates. The database recognized that women on lamotrigine presented with fetal malformations at a rate of $2.7 \%$ when compared to the general population, which is $1.62 \%$ (33). Another database in the UK suggests that there is a dose-dependent effect on fetal tetralogy at the concentration of $200 \mathrm{mg} / \mathrm{ml}$. The two databases confirmed that there is increased occurrence of facial cleft. The incidence of facial cleft in newborns with pregnant women treated with lamotrigine is at the rate of 9.9/1,000 people, which is significantly higher when compared to the control rate of $2 / 1,000$ people. A multitude of registries and databases have confirmed that there is a 2 - to 3 -fold increase in major malformations when there is in utero exposure to lamotrigine (34).

\section{Phenytoin}

Phenytoin is a hydantoin component which, when exposed in utero, can cause fetal hydantoin syndrome (FHS) in fetuses and newborns. This disorder causes and leads to multiple dysmorphic findings such as epicanthal folds, hypertelorism, broad flat nasal bridges, an upturned nasal tip, wide lips, distal digital hypoplasia, intrauterine growth retardation and mental retardation (35). A recent study showed that there was a prevalence of FHS in $11 \%$ of the children exposed to phenytoin in utero with $30 \%$ of the exposed children expressing at least some of the features of FHS. Therefore, the teratogenicity of phenytoin has been well-established (36).

\section{Topiramate}

Topiramate is a drug that is used for the treatment of epilepsy as well as migraines. While the data regarding the teratologic effects of topiramate is limited, a study has reported that the malformations resulting from its administration were at a rate of $4.8 \%$, and when administered with other drugs (polytherapy), that number went up to $11.2 \%$. The types of malformations resulting from topiramate include oral clefts and hypospadias, which were 11- and 14-fold higher, respectively, than the control (37). In addition, multiple cases of hypospadias, which is a birth defect of the urethra in males, have been reported for children that were exposed to topiramate in utero (38). The rates of major congenital malformations are different from one study to the next. In a study conducted by Ornoy (29) $9.8 \%$ of fetuses were found to have malformation rate, which is double the rate reported by other studies $(39,40)$. Researchers also found that pregnant women that were exposed to topiramate were found to have infants of lower birth weight as well as have a higher rate of spontaneous abortions (41). However, according to current literature, the rate of MCMs with exposure to topiramate is found to be similar to other AEDs.

\section{Vigabatrin}

Vigabatrin is an AED that is used specifically to treat specific refractoriness; its mechanism is to inhibit GABAtransaminase. While it is known that exposure to vigabatrin causes irreversible loss of vision in adult years, there is little research suggesting the consequence of its use in pregnancy. The scarce data available convey inconsistent findings of monotherapy exposure of vigabatrin (41). It was reported that approximately $15 \%$ of fetuses that were exposed to vigabatrin during pregnancy developed congenital malformations. There were some confounding factors in this study, including the fetal exposure to other AEDs. In addition, another study found that exposure to vigabatrin led to the malformation in children (42). However, once again, the women studied were also exposed to other AEDs. Finally, a study conducted by Turanli et al found no implications for children that were exposed to vigabatrin as fetus (43).

\section{Conclusion}

Appropriate management of epileptic pregnant women who are administered AEDs is important; seizure frequency may change during times like pregnancy, and both seizures and AEDs can have negative results for the fetus. We evaluated the effects of multiple AEDs including phenobarbital, valproic acid, carbamazepine, lamotrigine, phenytoin and topiramate. Some AEDs, such as valproic acid, are worse for the fetus than others. Newer AEDs, such as lamotrigine, need to be further evaluated in long-term studies for their effect on developing fetuses. Studies done on the use of phenobarbital suggests that it leads to a $4.3 \%$ increase in incidences of cleft palates in fetuses. Valproic acid administration was found to lead to neural tube defects, which lead to exencephaly. Study on carbamazepine found that it led to a $10-\mathrm{mm}$ decrease in fetal head circumference. Administration of lamotrigine during pregnancy led to a 2- to 3-fold increase in major malformations. Phenytoin led to a $11 \%$ incidence of FHS in fetuses. Topiramate led to oral clefts at a 11-fold higher rate in fetuses. Putting aside valproate, the major congenital malformation rate for pregnant women taking AEDs is generally double that of women not on medication; the risk for women on AEDs for having children with malformations is approximately $4 \%$. Hence, most pregnant women who are being administered AEDs will have no problems. Some ways to decrease the risk of birth defects are the use of folic acid and good obstetric care. Further studies are needed, however, to address cognitive effects of other AEDs; especially if these agents are used in increasing numbers during pregnancy $(1,3-5)$. 


\section{References}

1. Yerby MS: Clinical care of pregnant women with epilepsy: neural tube defects and folic acid supplementation. Epilepsia 44 (Suppl 3): 33-40, 2003.

2. Rogawski MA and Löscher W: The neurobiology of antiepileptic drugs for the treatment of nonepileptic conditions. Nat Med 10: 685-692, 2004.

3. Schmidt D, Canger R, Avanzini G, Battino D, Cusi C, Beck-Mannagetta G, Koch S, Rating D and Janz D: Change of seizure frequency in pregnant epileptic women. J Neurol Neurosurg Psychiatry 46: 751-755, 1983.

4. Crawford P: Best practice guidelines for the management of women with epilepsy. Epilepsia 46 (Suppl 9): 117-124, 2005.

5. Meador KJ, Baker G, Cohen MJ, Gaily E and Westerveld M: Cognitive/behavioral teratogenetic effects of antiepileptic drugs. Epilepsy Behav 11: 292-302, 2007.

6. Adab N, Kini U, Vinten J, Ayres J, Baker G, Clayton-Smith J, Coyle H, Fryer A, Gorry J, Gregg J, et al: The longer term outcome of children born to mothers with epilepsy. J Neurol Neurosurg Psychiatry 75: 1575-1583, 2004.

7. Meador K, Reynolds MW, Crean S, Fahrbach K and Probst C: Pregnancy outcomes in women with epilepsy: a systematic review and meta-analysis of published pregnancy registries and cohorts. Epilepsy Res 81: 1-13, 2008.

8. Jentink J, Loane MA, Dolk H, Barisic I, Garne E, Morris JK and de Jong-van den Berg LT; EUROCAT Antiepileptic Study Working Group: Valproic acid monotherapy in pregnancy and major congenital malformations. N Engl J Med 362: 2185-2193, 2010.

9. Morrow J, Russell A, Guthrie E, Parsons L, Robertson I, Waddell R, Irwin B, McGivern RC, Morrison PJ and Craig J: Malformation risks of antiepileptic drugs in pregnancy: a prospective study from the UK Epilepsy and Pregnancy Register. J Neurol Neurosurg Psychiatry 77: 193-198, 2006.

10. Samrén EB, van Duijn CM, Koch S, Hiilesmaa VK, Klepel H, Bardy AH, Mannagetta GB, Deichl AW, Gaily E, Granström ML, et al: Maternal use of antiepileptic drugs and the risk of major congenital malformations: a joint European prospective study of human teratogenesis associated with maternal epilepsy. Epilepsia 38: 981-990, 1997.

11. Vinten J, Adab N, Kini U, Gorry J, Gregg J and Baker GA; Liverpool and Manchester Neurodevelopment Study Group: Neuropsychological effects of exposure to anticonvulsant medication in utero. Neurology 64: 949-954, 2005.

12. Thomas SV, Indrani L, Devi GC, Jacob S, Beegum J, Jacob PP, Kesavadas K, Radhakrishnan K and Sarma PS: Pregnancy in women with epilepsy: preliminary results of Kerala registry of epilepsy and pregnancy. Neurol India 49: 60-66, 2001

13. Baker GA, Bromley RL, Briggs M, Cheyne CP, Cohen MJ, García-Fiñana M, Gummery A, Kneen R, Loring DW, Mawer G, et al; Liverpool and Manchester Neurodevelopment Group: IQ at 6 years after in utero exposure to antiepileptic drugs: a controlled cohort study. Neurology 84: 382-390,2015.

14. McVearry KM, Gaillard WD, VanMeter J and Meador KJ: A prospective study of cognitive fluency and originality in children exposed in utero to carbamazepine, lamotrigine, or valproate monotherapy. Epilepsy Behav 16: 609-616, 2009.

15. Gaily E, Kantola-Sorsa E, Hiilesmaa V, Isoaho M, Matila R, Kotila M, Nylund T, Bardy A, Kaaja E and Granstrom ML: Normal intelligence in children with prenatal exposure to carbamazepine. Neurology 62: 28-32, 2004.

16. HillDS, Wlodarczyk BJ,Palacios AM and Finnell RH: Teratogenic effects of antiepileptic drugs. Expert Rev Neurother 10: 943-959, 2010.

17. Rogawski MA and Löscher W: The neurobiology of antiepileptic drugs. Nat Rev Neurosci 5: 553-564, 2004.

18. Walker BE and Patterson A: Induction of cleft palate in mice by tranquilizers and barbiturates. Teratology 10: 159-163, 1974.

19. Ornoy A: Neuroteratogens in man: an overview with special emphasis on the teratogenicity of antiepileptic drugs in pregnancy. Reprod Toxicol 22: 214-226, 2006.

20. Mantovani A and Calamandrei G: Delayed developmental effects following prenatal exposure to drugs. Curr Pharm Des 7: 859-880, 2001

21. Wlodarczyk BJ, Palacios AM, George TM and Finnell RH: Antiepileptic drugs and pregnancy outcomes. Am J Med Genet A 158A: 2071-2090, 2012.
22. Bruni J and Wilder BJ: Valproic acid. Review of a new antiepileptic drug. Arch Neurol 36: 393-398, 1979.

23. Herrmann K: Effects of the anticonvulsant drug valproic acid and related substances on the early development of the zebrafish (Brachydanio rerio). Toxicol In Vitro 7: 41-54, 1993.

24. Rao S, Rajesh KR and Joseph T: Effect of antiepileptic drugs valproic acid, carbamazepine and ethosuccimide on exploratory behaviour in mice. Indian J Exp Biol 29: 127-130, 1991.

25. Eyal S, Lamb JG, Smith-Yockman M, Yagen B, Fibach E, Altschuler Y, White HS andf Bialer M: The antiepileptic and anticancer agent, valproic acid, induces P-glycoprotein in human tumour cell lines and in rat liver. Br J Pharmacol 149: 250-260, 2006.

26. Wlodarczyk B, Biernacki B and Minta M: [Teratogenic action of antiepileptic drug: 2-Propylpentanoic acid-effects on rat and hamster embryos cultured in vitro]. Ginekol Pol 72: 955-960, 2001.

27. Faiella A, Wernig M, Consalez GG, Hostick U, Hofmann C, Hustert E, Boncinelli E, Balling R and Nadeau JH: A mouse model for valproate teratogenicity: parental effects, homeotic transformations, and altered HOX expression. Hum Mol Genet 9: 227-236, 2000

28. DiLiberti JH, Farndon PA, Dennis NR and Curry CJ: The fetal valproate syndrome. Am J Med Genet 19: 473-481, 1984.

29. Ornoy A: Valproic acid in pregnancy: how much are we endangering the embryo and fetus? Reprod Toxicol 28: 1-10, 2009.

30. Diav-Citrin O, Shechtman S, Arnon J and Ornoy A: Is carbamazepine teratogenic? A prospective controlled study of 210 pregnancies. Neurology 57: 321-324, 2001.

31. Harding JJ and Timko JV: The use of psychotropic medications during pregnancy and lactation. The Foundation for The Global Library of Women's Medicine, Carlisle, 1999.

32. Holmes LB, Harvey EA, Coull BA, Huntington KB, Khoshbin S, Hayes AM and Ryan LM: The teratogenicity of anticonvulsant drugs. N Engl J Med 344: 1132-1138, 2001.

33. Cunnington $\mathbf{M}$ and Tennis $\mathrm{P}$; International Lamotrigine Pregnancy Registry Scientific Advisory Committee: Lamotrigine and the risk of malformations in pregnancy. Neurology 64: 955-960, 2005.

34. Tennis P and Eldridge RR; International Lamotrigine Pregnancy Registry Scientific Advisory Committee: Preliminary results on pregnancy outcomes in women using lamotrigine. Epilepsia 43: 1161-1167, 2002.

35. Allen RW Jr, Ogden B, Bentley FL and Jung AL: Fetal hydantoin syndrome, neuroblastoma, and hemorrhagic disease in a neonate. JAMA 244: 1464-1465, 1980

36. Adams J, Vorhees CV and Middaugh LD: Developmental neurotoxicity of anticonvulsants: human and animal evidence on phenytoin. Neurotoxicol Teratol 12: 203-214, 1990

37. Hunt S, Russell A, Smithson WH, Parsons L, Robertson I, Waddell R, Irwin B, Morrison PJ, Morrow J and Craig J; UK Epilepsy and Pregnancy Register: Topiramate in pregnancy: preliminary experience from the UK Epilepsy and Pregnancy Register. Neurology 71: 272-276, 2008.

38. Lindhout D and Omtzigt JG: Teratogenic effects of antiepileptic drugs: implications for the management of epilepsy in women of childbearing age. Epilepsia 35 (Suppl 4): S19-S28, 1994.

39. Tennis P, Chan KA, Curkendall SM, Li DK, Mines D, Peterson C, Andrews EB, Calingaert B, Chen HY, Deshpande G, Everage N, Holick CN, Meyer NM, Nkhoma ET, Quinn S, Rothman KJ and Esposito DB: Topiramate use during pregnancy and major congenital malformations in multiple populations. Birth Defects Res A Clin Mol Teratol 103: 269-275, 2015

40. Green MW, Seeger JD, Peterson C and Bhattacharyya A: Utilization of topiramate during pregnancy and risk of birth defects. Headache 52: 1070-1084, 2012.

41. Lombardo SA, Leanza G, Meli C, Lombardo ME, Mazzone L, Vincenti I and Cioni M: Maternal exposure to the antiepileptic drug vigabatrin affects postnatal development in the rat. Neurol Sci 26: 89-94, 2005.

42. Kroes HY, Reefhuis $\mathbf{J}$ and Cornel MC: Is there an association between maternal carbamazepine use during pregnancy and eye malformations in the child? Epilepsia 43: 929-931, 2002.

43. Turanli G, Celebi A, Yalnizoglu D, Topcu M, Topaloglu H, Banu A and Aysun S: Vigabatrin in pediatric patients with refractory epilepsy. Turk J Pediatr 48: 25-30, 2006. 